\title{
Variants in the IGF2BP2, JAZF1 and CENTD2 Genes Associated with Type 2 Diabetes Susceptibility in a Romanian Cohort
}

\author{
R Ursu ${ }^{1}$, P Iordache ${ }^{2}$, GF Ursu ${ }^{3}$, N Cucu ${ }^{4}$, V Calota ${ }^{5}$, A Voinoiu ${ }^{5}$, C Staicu ${ }^{5}$, D Mates ${ }^{5}$, E Poenaru ${ }^{1}$, A Manolescu ${ }^{6}$, V \\ Jinga ${ }^{7}$, LC Bohiltea 1 and VE Radoi ${ }^{1 *}$
}

${ }^{1}$ Carol Davila University of Medicine and Pharmacy Carol Davila, Romania

${ }^{2}$ Department of Epidemiology, Carol Davila University of Medicine and Pharmacy, Romania

${ }^{3}$ Emergency Military Hospital, Romania

${ }^{4}$ University of Bucharest, Romania

${ }^{5}$ National Institute for Public Health, Romania

${ }^{6}$ University of Reykjavik, Iceland

${ }^{7}$ Department of Urology, Carol Davila University of Medicine and Pharmacy, Romania

Submission: April 04, 2020; Published: April 22, 2020

*Corresponding author: VE Radoi, Medical Genetics, Faculty of General Medicine, University of Medicine and Pharmacy Carol Davila, Bucharest, Romania

Abstract

Diabetes mellitus (DM) is one of the leading causes of mortality and morbidity worldwide. Globally, 422 million adults were diagnosed in 2014 [1]. According to the PREDATOR study the prevalence of DM in Romania was 11.6\% [2]. DM is also an important socio-economic problem with high annual losses. In 2012, the estimations of the American Diabetes Association (ADA) regarding the total cost for DM patients` management was $\$ 245$ billion, of which $\$ 176$ billion in direct medical costs (hospitals, medical staff, treatment) and $\$ 69$ billion in indirect costs (inability to work, decreased productive capacity, absenteeism) [3]. The genetic factor is known to play an important role in the development of DM type 2 $[4,5]$. The concordance between monozygotic twins is about $70 \%$ and $20-30 \%$ among the dizygotic twins. The lifetime risk of developing DM type 2 is approximately $40 \%$ if one parent suffers from DM type 2 and $70 \%$ if both parents have the disease [6]. Numerous genes and loci have been described in association with the susceptibility for DM type 2, such as PPARG, HNF1A, HNF4A, KCNJ11/ABCC8, GCKR, SLC30A8, SLC16A11, TM6SF2, FT0, CAPN10, TCF7L2, PPARG, IRS1, IRS2, HHEX, SLC30A8, IGF2BP2, JAZF1, CENTD2, a.o [7-10].

The current study focuses on variants within the IGF2BP2, JAZF1, and CENTD2 correlated with type 2 diabetes in a Romanian cohort. The JAZF1 gene encodes for a nuclear protein which functions as a transcriptional repressor. JAZF1 supresses lipogenesis, increases lipolysis and decreases lipid accumulation in the adipose tissue, being an important factor in lipid metabolism. It also adjusts glucose metabolism and insulin sensitivity, with a role in glucose homeostasis [11-13]. The IGF2BP2 gene is located on the long arm of chromosome 3 (3q27.2). Various studies have shown the association between pathogenic IGF2BP2 variants and the susceptibility to type 2 diabetes [11,12,14]. According to literature, the CENTD2 (ARAP1) gene is significantly associated with increased plasma glucose levels and decreased glucose-stimulated insulin release, suggesting that the diabetic effect of this locus is mediated by impairing pancreatic beta cell function $[11,12]$.

Keywords: Diabetes mellitus type 2; Susceptibility; GWAS; IGF2BP2; JAZF1; CENTD2

\section{Purpose}

The current paper aims to study the involvement of JAZF1, CENTD2 and IGF2BP2 variants in the predisposition for DM type 2 in a cohort of Romanian men over 50 years old.

\section{Materials \& Methods}

The current study included 2024 male individuals, 250 with type 2 diabetes and 1752 non-diabetic controls (22 individuals with no data available). Blood samples were collected from all individuals included in the study for genetic testing. All subjects were of self-proclaimed Romanian nationality. The study protocols were approved by the National Ethics Committee of the Romanian College of Medical Doctors. A written informed consent was obtained from all the study participants. SNP genotyping was performed at DeCODE Genetics in Reykjavik, Iceland, using the Centaurus (Nanogen) platform on 716503 SNPs (Single Nucletide 


\section{Current Research in Diabetes \& Obesity Journal}

Polymorphisms). A p-value Hardy-Weinberg equilibrium threshold of 10-6 was used for data filtering. Also, markers with a minor allele frequency of less than 0.01 were excluded from the study. The statistical analysis of the results was performed using the Plink! v1.07 software.

\section{Results}

The GWAS results identified the following variants associated with type 2 diabetes (Table 1 ):

Table 1: The GWAS results identified the following variants associated with type 2 diabetes.

\begin{tabular}{|c|c|c|c|c|c|c|}
\hline Variant & Gene & Chromosome Location & $\begin{array}{c}\text { Mutant / Ancestral } \\
\text { Allele }\end{array}$ & Variant Type & p-Value & OR \\
\hline rs6766313 & IGF2BP2 & chr3:185749844 & T / C & Intronic & 0.002436 & 2.44 \\
\hline rs7790213 & JAZF1 & chr11: 72738204 & T / C & Intronic & 0.000622 & 1.391 \\
\hline rs10793039 & CENTD2 & chr3: 185749844 & T / C & intronic & 0.004664 & 1.314 \\
\hline
\end{tabular}

\section{Discussions}

IGF2BP2 (Insulin-like grow factor 2 mRNA-bindind protein 2, OMIM \#608289, chromosome location 3q27.2), rs6766313 $[11,12]$. Association of IGF2BP2 variants with DM type 2 has been documented in multiple studies [11,12,14-18]. In a research conducted by "The Diabetes Genetics Initiative of the Broad Institute of Harvard and MIT, Lund University, and Novartis Institutes for BioMedical Research", a number of 386,731 common SNPs were analyzed on a cohort of 1464 patients with type 2 diabetes and 1467 controls [15]. For each case, blood glucose, lipid metabolism, obesity and blood pressure were recorded. In collaboration with Finland - United States Investigation of NIDDM Genetics (FUSION) and Wellcome Trust Case Control Consortium / United Kingdom Type 2 Diabetes Genetics Consortium (WTCCC / UKT2D), they identified and confirmed a locus associated with type 2 diabetes in the second intron of IGF2BP2 [16].

The evidence for rs4402960 was weak but statistically significant at the initial scan $(p=0.034)$ but was pronounced in the replication samples $(\mathrm{p}=5.5 \times 10-9)$. Strong evidence was obtained for the same SNP, phenotype and genetic model by WTCCC / UKT2D ( $\mathrm{p}=10-4)$ and FUSION ( $\mathrm{p}=10-4)$ [16]. A metaanalysis on a Finnish cohort consisting of 1,161 type 2 diabetes cases and 1,174 controls revealed an increased susceptibility for DM type 2 for all included individuales carring the rs4402960 IGF2BP2 gene variant (OR = 1.14; P = 8.6 x 10-16) [16]. Based on GWAS data obtained from 1924 diabetic cases and a control lot of 2,938 individuals, "Welcome Trust Case Control Consortium" conducted a replication study on an additional 3757 DM type 2 cases and 5346 controls and by integrating their findings with other equivalent data from other international studies. The combined evidence from all studies ( $p=8.6 \times 10-16$ - genome-wide statistical significance - genome wide significance) established rs4402960 as a susceptibility locus for type 2 DM [17].

The IGF2BP2 rs6766313 variant identified through our study ( $p=0.002436,0 R=2.44$ ) (Table 1 ) is a variant of unknown clinical significance (class 3 variant, VUS), never being described before in literature [18-20]. JAZF1 (Juxtaposed with another Zinc finger gene, 1, OMIM \#606246, chromosome location 7p15.2-p15.1), rs7790213. A study on a Saudi Arabian cohort, which genotyped a group of 400 patients with type $2 \mathrm{DM}$ and a control group of 400 healthy individuals, investigated the association of JAZF1 (rs864745) with the susceptibility to type 2 diabetes. According to this study, the distribution frequencies of the $A A, A G$ and $G G$ genotypes of JAZF1 (rs864745) differ significantly among patients with type $2 \mathrm{DZ}$ and the control group $(\mathrm{p}<0.05)$. Heterozygous (AG) and mutant homozygous (GG) genotypes were independently and significantly associated with the susceptibility for type 2 DM after adjusting for age, sex, and body mass index $(\mathrm{OR}=2.1, \mathrm{p}=0.002$ and $\mathrm{OR}=1.9, \mathrm{p}=0.005)$ [21].

Our study revealed a statistical correlation $(\mathrm{p}=0.000622$, OR $=1.391$ ) of JAZF1 rs7790213 with type 2 diabetes (Table 1 ), the current research being the first study describing this variant $[19,20]$. CENTD2 / ARAP1 (Centaurin, Delta-2, OMIM \#606646, chromosome location 11q13.4), rs10793039. According to literature, CENTD2 (ARAP1) pathogenic mutations are significantly associated with increased plasma glucose values and decreased glucose-stimulated insulin release, suggesting that the diabetic effect of these variants is mediated by impairing pancreatic beta cell function [22].

The CENTD2 rs1552224 allelic variant has been reported to increase glucose levels after plasma TTGO at 30 minutes by $2.0 \%$ $(\mathrm{p}=2 \times 10-5)$ and by a $4.2 \%$ reduction of insulin release at 30 minutes after oral administration of glucose $(p=0.001)[22]$. The results of our study identified the rs10793039 CENTD2 variant (Table 1 ) in a statistical correlation with DM type 2 ( $p=0.004664$, $\mathrm{OR}=1.314)$, a variant of unknown clinical significance $[19,20]$.

\section{Conclusions}

The present study identified several possibly important variants associated with type 2 diabetes mellitus susceptibility, which migh provide insights into the genetic architecture of this pathology. The identified variants in the JAZF1, CENTD2 and IGF2BP2 genes, genes previously reported in association with DM susceptibility, have never been described before in literature. The validity of these results for the Romanian population is to be confirmed by undergoing replication studies. 


\section{Acknowledgements}

This work was supported by: CNCSIS-UEFISCSU, project PNIIIDEI, code ID 1184/2008, EU- FP7 Programme (ProMark project 202059) and by the EEA grant (ROMCAN project RO14-0017).

\section{References}

1. American Diabetes Association (2016) Classification and diagnosis of diabetes. Diabetes Care 39(Suppl 1): S13-S22.

2. Mota M, Popa SG, Mota E, Mitrea A, Catrinoiu D, et al. (2016) Prevalence of diabetes mellitus and prediabetes in the adult Romanian population: PREDATORR study. J Diabetes 8(3): 336-344.

3. Diamond J (2003) The double puzzle of diabetes. Nature 423(6940): 599-602.

4. Gerich JE (1998) The genetic basis of type 2 diabetes mellitus: impaired insulin secretion versus impaired insulin sensitivity. Endocr Rev 19(4): 491-503.

5. Ursu R, Iordache P, Radoi V (2016) Allelic variants associated with hypertension and hypertension-related clinical risk factors in a Romanian cohort of high blood pressure elder males. European Journal of Human Genetics 24(Suppl 1): 147.

6. Meigs JB, Cupples LA, Wilson PW (2000) Parental transmission of type 2 diabetes: the Framingham. Offspring Study. Diabetes 49(12): 22012207.

7. Udler MS (2019) Type 2 Diabetes: Multiple Genes, Multiple Diseases. Curr Diab Rep 19(8): 55.

8. Ali O (2013) Genetics of type 2 diabetes. World J Diabetes 4(4): 114123

9. Saxena R, Voight BF, Lyssenko V, Burtt NP, de Bakker PI, et al. (2007) Genome-wide association analysis identifies loci for type 2 diabetes and triglyceride levels. Science 316(5829): 1331-1336.

10. McCarthy MI (2010) Genomics, type 2 diabetes, and obesity. N Engl J Med 363(24): 2339-2350.

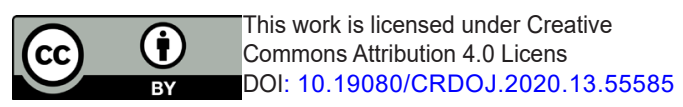

11. www.omim.org.

12. www.genecards.org.

13. Liao ZZ, Wang YD, Qi XY, Xiao XH (2019) JAZF1, a relevant metabolic regulator in type 2 diabetes. Diabetes Metab Res Rev 35(5): e3148.

14. Wu H, Liu N, Yang Z, Tao XM, Du YP, et al. (2014) IGF2BP2 and obesity interaction analysis for type 2 diabetes mellitus in Chinese Han population. Eur J Med Res 19: 40.

15. Diabetes Genetics Initiative of Broad Institute of Harvard and MIT Lund University, and Novartis Institutes for BioMedical Research (2007) Genome-wide association analysis identifies loci for type 2 diabetes and triglyceride levels. Science 316(5829): 1331-1336.

16. Scott LJ, Mohlke KL, Lori L Bonnycastle, Cristen J, Yun Li, et al. (2007) A genome-wide association study of type 2 diabetes in Finns detects multiple susceptibility variants. Science 316(5829): 1341-1345.

17. Zeggini E, Scott LJ, Saxena R, Voight BF, Marchini JL, et al. (2008) Metaanalysis of genome-wide association data and large-scale replication identifies additional susceptibility loci for type 2 diabetes. Nat Genet 40(5): 638-645.

18. Rao P, Wang H, Fang H, Gao Q, Zhang J, et al. (2016) Association between IGF2BP2 Polymorphisms and Type 2 Diabetes Mellitus: A Case-Control Study and Meta-Analysis Int J Environ Res Public Health 13(6): 574 .

19. https://www.ncbi.nlm.nih.gov/snp/.

20. www.snpedia.com/.

21. Alharbi KK, Khan IA, Syed R1, Alharbi FK2, Mohammed AK, et al. (2015) Association of JAZF1 and TSPAN8/LGR5 variants in relation to type 2 diabetes mellitus in a Saudi population. Diabetol Metab Syndr 7: 92.

22. Nielsen T, Sparsø T, Grarup N, Jørgensen T, Pisinger C, et al. (2011) Type 2 diabetes risk allele near CENTD2 is associated with decreased glucose-stimulated insulin release. Diabetologia 54(5): 1052-1056.

\begin{tabular}{|l|}
\multicolumn{1}{|c|}{ Your next submission with Juniper Publishers } \\
will reach you the below assets \\
- Quality Editorial service \\
- Swift Peer Review \\
- Reprints availability \\
- E-prints Service \\
- Manuscript Podcast for convenient understanding \\
- Global attainment for your research \\
- Manuscript accessibility in different formats \\
( Pdf, E-pub, Full Text, Audio) \\
- Unceasing customer service \\
Track the below URL for one-step submission \\
https://juniperpublishers.com/online-submission.php
\end{tabular}

